Sintisl: - Riv. I) Filosionia

27 N. 89 (2000): $349-374$

\title{
AS RECEPÇÕES DE TUGENDHAT \\ E HABERMAS DA DOUTRINA KANTIANA DO DIREITO
}

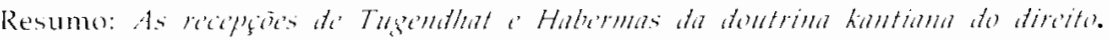
A Doutrina do Direito (1797) é um dos últimos trabalhos de Kant. Recomposto para uma nova editoração, o texto tem merecido a atenção de filósofos e teóricos do Direito. A presente contribuição examina a repercussão da obra jurídica de Kant nos escritos recentes de Tugendhat e Habermas. O artigo privilegia as relações entre Direito e Moral e procura mostrar a originalidade da concepção normativa de Kant para a Filosofia do Direito.

Palavras-chave: Doutrina do Direito, Razão prática, Filosofia do Direito, Kant.

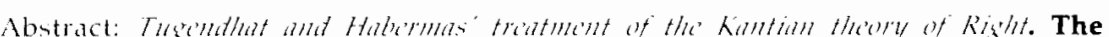
Doctrine of Right (1797) is one of the last works of Kant. Revised for a new edition, the text deserved the attention of philosophers and theorists of Right. This paper examines the repercussion of Kant's juridical work in recent writings by Tugendhat und Habermas. The article privileges the relations between Right and Morals and tries to show the originality of Kant's normative conception for the Philosophy of Right.

Key-words: Doctrine of Right, Practical reason, Philosophy of Right, Kant.
\end{abstract}




\section{Introdução}

A primeira parte da Mefoficiza dos costumes pode ser lida como uma seqüência de aporias', ou como última etapa de um pensamento crítico². Avaliada à luz da segunda Critica, a Dontrina (to Dircito contém enfoques originais, dentre os quais se destacam a dupla legislação moral, a auto-suficiência recíproca dos seres humanos e os pontuais indicativos de uma dedução imperativa da razão prática pura.

Os textos recentes sobre moral e direito de Tugendhat (1930-) e Habermas (1929-) abordam questōes clássicas da filosofia prática de Kant (1724-1804). Em relação à ciência kantiana do direito, ambos os autores são comedidos, quando não ostensivamente evasivos. A conálise critica do imperativo categórico, levada a cabo por Tugendhat sobre o eixo de Fundamentaçă ì mitatisica dos costumess (1785) e Metatision dos costuml's (1797), passa ao largo da concepçào jurídica de Kant. O recurso à filosofia kantiana do direito, feito por Habermas ao longo da reconstrução do direito moderno, mantém-se discreto em relação aos estudos que o texto kantiano tem merecido nas últimas décacłas por parte da crítica especializada.

\section{A proposta de um senso normativo unitário}

Tugendhat demarca o terreno sobre o qual incide sua crítica, desonerando Kant "das obrigações e excentricidades formalísticas (...)

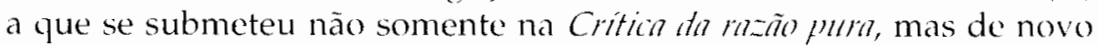
na Criticn ath raño pritica (...)"3, registrando que não conhece ninguém que creia na distinção entre mundo natural e mundo inteligível"t, e deixando seu alter ço filosófico protocolar que "a idéia de Kant de uma motivação moral pura (....) é de todo indiscutivel (ist ä̉lliş inthiskutuloct)"

A incidência crítica de Tugendhat toca num dos pontos nevrálgicos da moral kantiana, onde a segunda Crifica cruza com a Doutrima do Dircito,

H. G. Degicis, Die Aporien der Rechtslehre Kanls, Stuttgart: Reclam, 1983.

"Kt:Rstivi, Wohlgeordnete Freihcit. Immanuel Kants Rechts und Staatsphilosophie, Berlin/New York: de Gruyter, 1984

E. Trit:inht, Vorlesungen über Ethik, Frankfurt a/Main: Suhrkamp, 31995, 98.

Trad. do alemão por Joãosinho Beckenkamp, Petrópolis: Vozes, 1997, 106.

- luk:. Ética e justificação, Veritas v. 44, n. 1 (1999): 13.

"Inem, Dialogr in Leticia. Frankfurt a/Main: Suhrkamp, 1997, 121. 
e Kant fala distinta ou indistintamente de Wille (vontade) e ou de Willkiur (arbítrio). As duas preleçōes, em Liçoe's solle Ética (1993), nas quais Tugendhat faz o acerto de contas com o imperativo categórico, concluem ambas' centradas sobre a relação problemática entre vontade e arbítrio. Ao desincompatibilizar a definição kantiana de livre-arbítrio de sua proveniência jusnaturalista, Tugendhat moraliza a liberdade como "único, originário direito que cabe a cada homem em virtude de sua humanidade $e^{\prime \prime}, \mathrm{com}$ a liberdade de escolha do indivíduo de fazer ou não fazer parte da comunidade moral. A troca do conceito de vontade livre pela faculdade do livre-arbítrio não é providenciada em Tugendhat pela idéia do direito - como em Kant -, mas pelo uso trivial do termo "normalidade". Depois de assinalar que o conceito de liberdade utilizado na Fundannentaçion ì metafisica des costumes trata da liberdade da vontade e não da liberdade do arbítrio, Tugendhat assegura

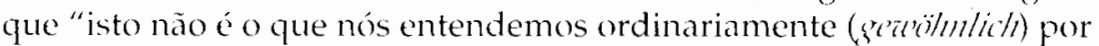
liberdade, uma liberdade do sim-não, mas um ser livre de (da sensibilidade), que é ao mesmo tempo um ser livre para (a razão)"

Com isso, a témillrth verificacionista da moral está assegurada. Os integrantes da comunidade moral nào apenas revelam-se como parceiros de direito, mas são também bons parceiros uns dos outros. Viceversa, cada comunidade moral é necessariamente para Tugendhat uma comunidade jurídica, ao criar um Estado de direitos (humanos) como "representação unitária de todos (als cinhteitliche Vertretumg aller)". Munido com "o direito moral no sentido forte", o representante político tem à disposição todas as sanções penais do Estado de direito". Na resolução de problemas morais, Tugendhat defende o emprego de uma razão fraca, tendo em vista a incognoscibilidade teórica do fato kantiano da razão e a indecidibilidade prática de ajuizar sobre a irracionalidade de comportamentos amorais. O reforço cognitivo, atribuido por Tugendhat ao chamado dircito moral, a feta tão pouco os integrantes da comunidade moral quanto o seu eventual observador. Se a comunidade moral for passivel de uma descrição racional, a ausência do sentimento de culpa, ressentimento e indignação em algum de séus membros só

\footnotetext{
"Iowa, Vorlesungen über Ethik, 130 e 160; versão portuguesa, 139 e 170-171, respectivamente.

- Kavt, Metaphysische Anfangsgrïnde der Rechtslehre (237, 32-34), Hrsg. von Bernd Ludwig, Hamburg: Meiner, 1986, 47: "Freihcit $1 . .1$ ist dieses einzige, ursprüngliche, jedem Menschen, kraft seiner Menschheit, zustehende Recht". - Triandhar, op. cit., 160; versào portuguesa, p. 170.

"Ibidem, 350; versão portuguesa, 377: "Haveria portanto uma obrigaça moral para a criação de uma instáncia legal como representação unitária de todos e isto significa: resultaria (a ser definido a partir dai em suas tarefas) uma exigência moral para a criaçào de um Estado. O direito moral pode. portanto, ser perfeitamente compreendido no sentido forte, mas somente de tal maneira, que dai resulte uma obrigação moral coletiva, uma correspondente instáncia jurídica a ser institucionalizada".
} 
poderá alterar a racionalidade coletiva, na medida em que o agir de um deles for descrito como irracional. Se, por outro lado, não for possível descrever racionalmente um suposto lack of moral sense, a comunidade moral somente deixa de ser racional, na medida em que nenhum de seus atores fica excluído da descrição coletiva. Por identificar validade com gênese, Tugendhat pode, por um lado, atribuir à primeira uma racionalidade fraca, remetendo a normatividade moral à sua respectiva procedência, e pode, por outro, conferir ao direito uma racionalidade forte, induzindo o normativismo jurídico das sanções sociais. "O que ocorre quando se transgride uma moral", verifica Tugendhat, "é que se experimenta uma sanção social"10.

Ao lidar com a figura do oportunista inveterado (Trittbrettfahrer) que, como membro da comunidade moral, persegue tão-somente interesses particulares, Tugendhat oferece uma resolução moral para um problema a que Kant dá a prototípica solução jurídica. No capítulo II de Diálogo em Letícia (1997), Tugendhat confronta seu parceiro filosófico com a idéia de uma comunidade moral composta exclusivamente de frec-riders. Distinguindo entre fundamentação e motivação, o parceiro se propõe a fundamentar o sistema moral, observando: "(...) e esse funciona de fato somente como comunidade moral, na qual todos ou a maioria, por serem desse modo, exigem uns dos outros reciprocamente que assim sejam, e isso eles só podem, na medida em que expressam os sentimentos morais, mas isso eles podem, sem que os tenham". Ao que o autor do livro responde: "Já entendo, e está bem de acordo com minha linha de distinguir nitidamente entre a pergunta relativa à fundamentação e aquela da motivação"11. Na verdade, Tugendhat está concordando com a solução que o parceiro deu ao problema da criação do Estado, do qual Kant diz que, "por mais áspero que soe, tem solução, inclusive para um povo de diabos (contanto que tenham entendimento) $)^{\prime \prime 2}$.

Tugendhat soluciona problemas de fundamentação moral com um Faktum do entendimento jurídico, vale dizer, assim como homens que agem por respeito à lei moral continuam, em Kant, desconhecendo quão livres de fato são, of frę-rider da comunidade moral ignora, ao expressar sentimentos morais que não tem, que é de fato um integrante racional da coletividade jurídica. A imunidade da comunidade moral contra a eventual iriacionalidade de seus membros corresponde em Tugendhat ao medo que o indivíduo tem de ficar isolado na comunidade à qual

\footnotetext{
11) Tugiendhat, Zum Begriff und zur Begrüdung von Moral, in Bellut - MullerScноц. (Hrsg). Mensch und Moderne, Würzburg, 1989, 147.

${ }^{11}$ IIJEM, Dialog in Leticia, 43-44.

${ }^{12}$ Kant, A paz perpétua, in Kleinere Schriften zur Geschichtsphilosophie, Ethik und Politik, Hrsg, von Karl Vorländer, Hamburg: Meiner, 1973, 146. Trad. do alemāo por Artur Morão, Lisboa: Edições 70, 1988, p. 146.
} 
deve sua identidade qualitativa ${ }^{13}$. O contra-senso desse tipo de resolução normativa está no senso aristotélico atribuído por Tugendhat à moderna concepção de direito. Como nenhum cidadão do Estado de direito pode ser expatriado, Tugendhat neutraliza o egocentrismo do anthropós hobbesiano pelo medo da excomunicação moral, ou seja, sentimentos que para Hobbes (1588-1679) amparam o Estado moderno servem em Tugendhat para manter de pé o princípio do respeito universal inerente à comunidade moral ${ }^{14}$.

O ponto de contato entre o encaminhamento que Tugendhat dá ao problema e a posição que Kant assume frente ao mesmo encontra-se na divisão da metafísica dos costumes em geral, quando Kant pergunta por que a doutrina dos deveres não constitui também a doutrina dos direitos, uma vez que uns remetem aos outros ${ }^{15}$. Contrariamente a Kant, que desenvolve o conceito de direito procedendo do imperativo categórico, Tugendhat faz o caminho inverso, provindo de constelações jurídicas para a legislação moral. A lição "Direitos Humanos", em Liçỡs sobre Ética, contém uma análise minuciosa da constituição reciprocamente imparcial dos direitos na esfera legal, para chegar à "unidade do conceito do direito", uma base programática dos "direitos morais (moralische Rechte)" ", cujo sujeito não é visto apenas como mero objeto de nossas obrigações", mas "compreendemos nossa obrigação como um reflexo do seu direito". Tugendhat admite que falar em direitos morais só pode ser feito "em sentido fraco", o que "talvez não seja muito, mas é alguma coisa". Depois de perguntar se o fortalecimento da moral, assim como descrito, é desejável, Tugendhat responde a si mesmo, observando: " $(. .$.$) a resposta somente poderá ser formulada positiva-$ mente, e por isso esses direitos existem (tão rapidamente pode-se aqui concluir a existência) e eu, portanto, tinha razão para compreender assim, de antemão, a moral do imperativo categórico"'to.

Como para Tugendhat a gênese coletiva da moral depende, confessadamente, da reconceituação do imperativo categórico, o crítico da moral kantiana altera de saída a constelação da Doutrina do Direito. Se o dever de um agente moral reflete o direito de um agente jurídico - como Tugendhat apostrofa - entender de antemão a moral do impe-

\footnotetext{
1:3 "Exkommunikation" (excomunicação) e "Anstand" (decência) são as ferramentas críticas de Tugendhat contra uma concepção liberal e/ou particularista de moral. Tugendhat, Dialog in Leticia, 83-101.

${ }^{14}$ Para uma discussão crítica da posiçào kantiana, cf. K. Günther, Kann ein Volk von Teufeln Recht und Staat moralisch legitimieren? Rechtshistorisches Journal, Heft 10 (1991): 233-267.

1.5 KAvт, Metaphysische Anfangsgründe der Rechtslehre (239, 13-16), 31: "Warum wird aber die Sittenlehre (Moral) gewöhnlich (namentlich von Cicero) die Lehre von de Pflichten und nicht auch von den Rechten betitelt? Da doch die einen sich auf die anderen beziehen".

16 Tugendhat, Vorlesungen über Ethik, 346-347; versão portuguesa, pp. 374-375.
} 
rativo categórico como chave interpretativa desse reflexo implica neutralizar a limine a moral por uma tipicidade jurídica, segundo a qual direitos correspondem a dev'eres e vice-versa, e acolher uma noção uniforme de normatividade como adequada ao intuicionismo moral. O reforço (Vorstïrkıng's) juridico, com que Tugendhat socorre a pestertiorio imperativo categórico, repensa a obrigatoriedade moral como caudatária da obrigação jurídica, certificando à primeira uma falência racional a p'rori. O qué, para Kant, só a razão está em condição de fazer - mover o homem por respeito à lei moral - passa a ser aplicado simétrica, imparcial, perfeita e reciprocamente por parte de um homem sobre outro e, em nome de todos, pelo Estado como instância última da coercibilidade coletiva. Deslocado pela escolha de integrar ou não uma moral comlnmunity, o princípio kantiano do direito - liberdade definida como "independência frente ao constrangimento de qualquer outro"ss - perde a qualidade de um princípio jurídico de universalização, substituído que se encontra pela necessidade do indivíduo de decidir se aceita ou não a concepção de sua comunidade moral, isto é, "está de acordo com e'ste acervo de regras morais"'"

Ou o imperativo categórico é uma ficção kantiana, não merecendo maior atenção do que qualquer outra idéia, ou "ele se sustenta por si mesmo (sonst be'steht e's cturch sich sellhst)", como Kant afiança no prefácio da segunda Crítica, depois de esclarecer que a razão prática pura "pres-

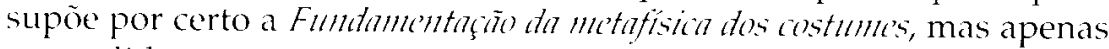
na medida em que nos familiariza de maneira preliminar com o princípio do dever, e apresenta e justifica uma determinada fórmula do mesmo"'2!. Como, por razões concepcionais, Tugendhat não entra no mérito da Critica da maino prática, seu rearranjo do imperativo categórico

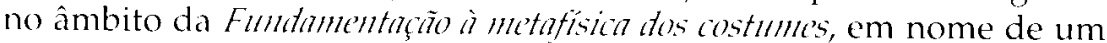
conceito trivial de razão, revela traços analíticos de um puritanismo apriorístico, socorrendo a suposta evidência de nossas intuições morais com a empiricidade da coerção social. O autor de Diálog̣o ('lll Letícir sugere amoralizar ('ntmoralisich'n) as esferas anônimas da sociedade, compostas que são por indivíduos que elegem não fazerem parte da comunidade moral, "e reforçar simplesmente os controles externos" sobre corrupção, sonegação de impostos e toda sorte de comportamentos oportunistas, fazendo jus a uma moral de conseqüências, indepen-

\footnotetext{
1: Inem, Dialog in Leticia, 27-57 e 83-101, respectivamente.

"KA.N', op. cit., (237, 30-31), 47: "Freiheit (Unabhängigkeit von eines Anderen nötigender Willkür)".

19 Tlikindhat, op. cit., 120: "(..) mit diesem Set von moralischen Regeln".

KAvT, Kritik der praktischen Vernunft, Hrsg. von Karl Vorländer, Hamburg: Meiner, 91969, 8-9. Trad. do alemāo por Artur Morão. Lisboa: Ediçōes 70, 1989, p. 16.
} 
dentemente do fato de haver ou não haver à disposição proibições sancionadas por meio de normas ${ }^{21}$.

Não obstante acentue que tal resolução uniforme para infrações legais no seio da sociedade de massas não aposenta de todo posições kantianas $^{22}$, Tugendhat uniformiza à moda aristotélica ${ }^{23}$ a convivência dos cidadãos, em desconsideração à moderna noção de coerção jurídica centrada na liberdade individual, seja ela entendida como inata ou tenha teor constitucional. Uma norma não mais endereçada a indivíduos, mas comprometida com a excelência de determinada situação social, designa o conceito aristotélico de lei, congregando numa pólis membros destituídos de individualidade moral e de personalidade jurídica. Tugendhat concede que a discriminação secundária, legitimando o tratamento desigual de desiguais, não se justifica nem mesmo com um imperativo moral conseqüencialista.

A concepção aristotélica de lei fere a dogmática jusnaturalista e/ou constitucional do direito moderno. A discriminação secundária complementa no filósofo grego o tratamento eqüitativo de desiguais, chamada justiça distributiva. A geração da igualdade, ratificando por regras de proporcionalidade a desigualdade inata à pólis grega, é corrigida conseqüentemente por uma justiça comutativa que retribui aos desiguais um tratamento desigual, ou seja, estabelece quais distribuições desigualitárias de bens são justas e quais distribuições igualitárias de bens são injustas. Insolúvel no âmbito de uma concepção tradicionalista de ética, Tugendhat repõe as noções de moral commulmity e de direitos morais à luz do moderno posicionamento normativo acerca da igualdade dos seres humanos, pleiteando por uma comunidade moral aberta a todos os homens e onerando a distribuição desigual de bens com a apresentação de boas e convincentes razões para um tratamento desigual ad hoc ${ }^{2 t}$. Tomando por analiticamente dada a congruência entre obrigações e direitos, Tugendhat configura o igualitarismo como pedra de toque de um dever-ser recíproco que assegure o mesmo respeito e a mesma consideração a todos os homens. À primeira vista, a proposta não apenas subverte a ordem da convivência de desiguais e desvincula o direito moderno de qualquer filiação jusnaturalista, mas constitui-se também em alternativa à posição de Kant, que não correlaciona simplesmente deveres morais com direitos jurídicos e mantém separados os deveres de direito (Rechtspflichtenl)

\footnotetext{
21 Tugendhat, op. cit., 120-143.

t2 Ibidem, 132-136.

23 Cf. J. Beckenkıup, Tugendhat, leitor de Aristóteles, Dissertatio, n. 3 (1996): 5165.

${ }^{24}$ Tugendhat, Igualdade e universalidade na moral, in Brito - Heck, Ética e politica, Goiânia: Editora UFG, 1997, 45-60.
} 
officia iuris) dos deveres de virtude (Tugendpflichten/officia virtutis s.

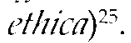

A concepção de uma comunidade moral, de acordo com a qual todos os homens "devem ser considerados moralmente iguais - quer dizer, iguais em direitos - apesar de suas desigualdades empíricas" ${ }^{26}$, dispensa decerto o procedimento aristotélico de promover a igualdade mediante um tratamento igualitário dos desiguais. A equivalência normativa entre igualdade moral e jurídica, assumida por Tugendhat, só não perfaz uma redundância porque a comunidade moral não é universal por definição, mas apenas "tem que ser entendida como aberta" ${ }^{27} \mathrm{e}$, enquanto tal, o universalismo constitui mero corolário do igualitarismo. Da excelência de uma pólis moral e juridicamente igualitária resulta uma vocação universalista do organismo normativo, de modo que nenhum de seus membros tem argumentos à mão para justificar a não integração de alguém que dele deseje participar. "Se chegarmos a um outro continente ou a um outro planeta", escreve Tugendhat, "e encontrarmos gente que queira tomar parte de nossa comunidade moral, não poderemos excluí-los pela razão de não podermos estabelecer direitos desiguais, ou seja, por não podermos lhes justificar isto" ${ }^{\prime 28}$.

Desde que o terceiro tenha querido participar da moral community, a não justificação de sua inclusão é, em Tugendhat, correlata da subordinação recíproca à igualdade por parte dos integrantes da comunidade igualitária ${ }^{29}$. A recusa de um novo bom cooperador implicaria o desaparecimento do corpo normativo. Como, para Tugendhat, a deveres correspondem direitos, fica impossível aceitar a recusa, pois se a todos os membros da comunidade moral assistem os mesmos direitos, nenhum deles pode ter a obrigação de viabilizar o desaparecimento da comunidade moral.

Do ponto de vista dos destinados ao ingresso, o igualitarismo impõe aos integrantes da comunidade moral o dever deôntico de não impedir a ninguém uma parceria moral. O caráter universalista é tendencial porque a obrigação de não sustar a participação de novos membros depende da escolha, por parte do terceiro, de integrar a comunidade moral. O igualitarismo e o universalismo não são equivalentes normativos mas, dadas as circunstâncias, suas relações configuram-se no tipo de interdependência que estabelecem entre si. A proposta igualitária de Tugendhat só poderia reivindicar tratamento normativo se

25 Kant, Metaphysische Anfangsgründe der Rechtslehre (239, 2-12), 31.

thi TugiendHat, op. cit., 50

Ibidem, 59.

Ibidem, 59-60

29 Tughndat, Reflexões sobre o que é que significa justificar juizos morais, Goiània, 1998 (texto mimeo). 
concedesse à comunidade moral o direito de impor a terceiros a entrada na comunidade. Tal direito seria correlativo à obrigação de alguém ser membro da comunidade moral. Condicionado como está à opção do indivíduo pelas regras de jogo morais da comunidade, o normativismo igualitário de Tugendhat só pode ser descrito à luz da decisão que um agente toma em favor de uma comunidade regida pela cláusula da reciprocidade. Deôntica é apenas a obrigação thğratie de não fechar as portas da comunidade moral a ninguém que queira dela participar. Em contrapartida, máximas consideradas aptas a valer como norma universal não impõem obrigaçôes, mas permitem aos membros da comunidade moral agir em conformidade com elas ${ }^{31}$. Tugendhat declina, com razão, imputar aos integrantes da comunidade moral a não ocorrência de parcerias, e tampouco os responsabiliza mundo afora por eventuais opções em desfavor da comunidade moral. Sob este aspecto, ele faz uso de uma concepção fraca de razão, caudatária da faculdade de fazer ou deixar de fazer dos seres humanos.

Uma matriz diversa de racionalidade é exigida em relação àqueles domínios da comunidade moral nos quais as pessoas suspendem a cláusula da reciprocidade, revidam o sistema de obrigaçōes mútuas e continuam usufruindo dos benefícios da organização coletiva, acobertados pelas interfaces anônimas da interação social. Entendida como tendencialmente aberta para fora, Tugendhat verifica que toda comunidade moral permanece igualmente aberta em sentido contrário, quer dizer, por um lado ela acolhe adesões provindas de fora e, por outro, sofre de defecções oriundas em seu seio. Ao passo que os $1 / \mathrm{h}^{\prime \prime}$ conllers confirmam para Tugendhat a vocação universalista da comunidade moral, os sonegadores de impostos, os usuários "frios" de coletivos (Schatarzfahrer) e as legiões de pequenos e grandes impostores minam por dentro o princípio da filiação normativa entre universalismo e igualitarismo, intrínseca à constituição de toda ongroving morn commlunity.

No capítulo final de Diálogro em Léticia, Tugendhat retoma a constelação triádica dos sentimentos morais e relativiza a correlaçào entre motivos e indignação, ancorada sobre a verificação de que a cada infração moral correspondem sanções sociais, um princípio programático dé seu uniformismo normativo. Como rejeita o imperativo categórico e a noção kantiana da vontade livre ("da qual se originam todas as leis morais e com isso também todos os direitos e deveres") ", Tugendhat dispensa também o princípio do direito de Kant, segundo o qual o livre-arbítrio de cada um é compatível com a liberdade de qualquer homem de

\footnotetext{
6f. A. Whilmer, Ethik und Dialog, Frankfurt a/Main: Suhrkamp, 1986, p. 2129 e 120 , respectivamente.

$: 31$ KANT, Metaphysische Anfangsgründe der Rechtslehre (239, 17), 31.
} 
acordo com uma lei universal, recorrendo ao velho mestre Aristóteles e a sua noção perfeccionista de bom. Depois de registrar que não se deve assumir a posição aristotélica relativa a um "ser-bom" (Gutsein) cuja excelência se encontre estruturalmente desconectada de sua fundamentação intersubjetiva, Tugendhat assegura que a indicação do Estagirita, "de que - não para todos, mas para os 'bons' - não importa qualquer aplauso, mas o aplauso daqueles aos quais assiste competência de juízo, encerra o essencial", e arremata: "Apreciar, tomar por bom é por certo outra coisa do que (o) achar-agradável, e contém uma reivindicação objetiva" "32.

O livro termina na aporia, sem conseguir encaminhar satisfatoriamente o problema da corrupção e desenvolver uma fórmula adequada para a discriminação secundária. $\mathrm{O}$ interlocutor se despede do amigo, constatando: "Existem decerto perspectivas das quais se pode primu fincie dizer que contêm uma regra proporcional de distribuição desigual, aceitável igualmente para todos, mas há vários desses pontos de vista, e eles se contradizem entre $\mathrm{si}^{\prime \prime}$. Suas últimas palavras recordam ao amigo que há uma lição de casa por fazer: "Aqui seria, portanto, necessária uma metaperspectiva, e que feição ela deve assumir?"33

Sem revidar a posição de que não há um stantart de moral na Modernidade ${ }^{34}$, Tugendhat retoma a questão da fundamentação de um sistema de exigências mútuas em dois planos distintos. $\mathrm{O}$ primeiro descreve o caminho seguido pela gênese da justificação de juízos morais individuais, e no segundo são abordados conflitos entre diferentes concepções de justificação moral. Diferentemente do que ocorre no lecel inicial, o tratamento dado às concepções de justificação não mais tolera disparidades morais causadas por condições psicológicas, históricas e sócio-econômicas subjetivamente diversas. "Esse caminho não é possível", observa Tugendhat, "quando nós mesmos nos encontramos dentro duma moral e dentro de exigências recíprocas" ${ }^{\prime \prime 5}$. Depois de rejeitar o paralelo analógico entre um exame de juízos morais e o exame de juízos fácticos ou estéticos, e considerar insatisfatório o apelo aos predicados "bom" e/ou "racional", Tugendhat consolida o plano genético dos juízos morais com uma definição de autonomin coletiza. Tal

"Tugendhat, Dialog in Leticia, 124.

33. Ibidem, 142-143.

34 Tugendhat, Gibt es eine moderne Moral? Zeitschrift für philosophische Forschung 50 (1996): 323-338; Em que a filosofia pode contribuir para a política, in BRito - HeCk. op. cit., 43: "Não podemos dizer que a moral particularista é má e a moral universalista é boa, porque, na minha opinião, não há um standard do que seja absoluto. A única coisa que podemos dizer é que a moral nacionalista, por exemplo, tem determinadas implicações e que se, de outro lado, queremos ter outras implicaçōes, então temos que ser universalistas".

35 Tugendhat, Reflexões sobre o que é que significa justificar juizos morais, Goiânia, 1998, 3 (texto mimeo). 
autonomia "não consiste", escreve Tugendhat, "como parece na ética de Kant, em que cada indivíduo se impõe a ordem ele mesmo e da mesma maneira no caso de todos os outros, mas os indivíduos se superpõem e se subordinam reciprocamente a essa ordem" ${ }^{\prime 36}$. A consolidação da autonomia dos indivíduos na coletividade é verificada no afeto moral. "Fixamos a bandeira num lugar e vemos depois como esse lugar se pode comparar com outros similares", sentencia Tugendhat depois de haver esclarecido que "a descrição do afeto e a de seu objeto proposicional são dois lados da mesma coisa"37. A vinculação intersubjetiva da autonomia coletiva não se encontra, assim, apenas mediada pelo indicativo "para todos", mas atesta possuir uma estrutura afetiva, e somente nesse sentido preciso está justificada igualmente para todos. A primeira alternativa concede um tratamento meramente cognitivo à moral, ao passo que Tugendhat não crê numa cisão entre cognitivo e emocional, a qual não cansa de criticar na filosofia moral de Kant.

Concluído o processo de admissão do indivíduo na comunidade moral, "fica aberto", segundo Tugendhat, "o campo para outras maneiras de justificação", ou seja, "põe-se uma pergunta de justificação num segundo nível $(\ldots)^{\prime \prime 38}$, no qual a posição universalista concorre com o contratualismo conseqüente e o comunitarismo contemporâneo, não evitando o confronto com o veredicto de Nietzsche (1844-1900) de que "o universalismo seria uma moral que ficaria ao lado dos desfavorecidos" ${ }^{\prime \prime 39}$. Tugendhat não logra priorizar uma justificativa igualitária que implique universalidade senão negativamente. A liberdade de aderir à comunidade moral, ou permanecer omisso perante ela, desaparece tão logo o indivíduo toma parte dela, com o argumento de que a autonomia coletiva constitui um sistema de não discriminação, vale dizer, o livre-arbítrio justifica-se como ato distintivo por ocasião do ingresso na comunidade moral, mas, uma vez dentro dela, fica vedado seu uso"t). Tugendhat reconhece que do afeto na moral universal "falei somente em seu aspecto negativo $(. . .)^{\prime \prime \prime 1}$. O texto acaba privilegiando uma relação intersubjetiva de equilíbrio como "a mais desejável, (...) um dado último que não dependeria de nenhum outro"t2, e conclui melancolicamente reportado ao conceito de justiça em Platão, levando água ao moinho de quem sempre soube que Cálicles tem os melhores trunfos contra a moral como uma invenção de escravos.

\footnotetext{
36 Ibidem, 9.

37 Ibidem, 11.

${ }^{3}$ Ibidem, 12-13.

i. Ibidem, 15.

4) Ibidem, 16.

${ }^{41}$ Ibidem, 17.

42. Ibidem, 19.
} 
Em seu texto recente, "O contratualismo na moral" (1998), Tugendhat se vale do conceito de justiça para sustentar uma concepção forte de autonomia coletiva, mediante um acordo capaz de justificar "as regras morais como condição da cooperação humana" +3 . Tugendhat distingue o contrato moral de um contrato normal resultante de negociação, no qual os contratantes se comprometem a fazer algo, "normalmente não a mesma coisa que o outro" ${ }^{+4}$. Força normativa unitária, o contrato moral adquire não só por assegurar a não violação de promessas feitas, mas sobretudo por intersubjetivar sentimentos morais como exigências mútuas. Para Tugendhat, o contrato moral providencia tal sistema recíproco de correspondências emotivas porque introduz um conceito de aferição não particularista, denominado justiça. A racionalidade moral do contrato de segundo nível está tão inexoravelmente comprometida com o conceito de justiça que Tugendhat considera ilegítima a criação de uma comunidade moral por intermédio de um contrato de primeiro nível, produto, segundo D. Gauthier (1932-), de uma negociação entre as partes ${ }^{45}$. Como critério intrínseco de geração do contrato moral, a justiça é detectada por Tugendhat no fato de que os indivíduos e grupos não apenas falam em interesses, mas também daquilo que lhes é irremediavelmente recíproco. "A conclusão é", escreve Tugendhat, "que a moral contratualista tem que ser entendida como universal, uma vez que se percebe que tem que ser justificada reciprocamente"th.

Eliminando qualquer suspeita de que a constituição de sistemas morais igualitário-universalistas depende de hábitos ou preferências, Tugendhat revela ser um positivista ético mais decidido do que Hegel, o qual ainda pensa a realização da idéia ética consubstanciada no Estado. Tugendhat constata que também a consciência pode ser clareada à luz do contrato moral. Tendo ponderado que a disposição para a indignação e ao sentimento de culpa parece remeter a fatores biológicos, Tugendhat verifica que é o próprio mecanismo do contrato moral "que cria o motivo de querer evitar os afetos negativos dos outros, e este motivo depois se pode desenvolver numa maneira autônoma de atuar, de tal maneira que a pessoa não tem que aparecer desprezível para si mesma" ${ }^{\prime \prime}$. Tal proposta de contrato moral, como metajustificação do contratualismo jurídico, pressupõe que toda constelação de exigências mútuas possui caráter prescritivo uniforme, vale dizer, configura antecipadamente a descrição de procedimentos justos com base em obrigações que geram direitos correspondentes.

4.3 Tugendhat, O contratualismo na moral, Caxambu, 1998, 2 (texto mimeo).

it Ibidem, 6

45 Ibidem, 8-9. Cf. D. Galthier, Morals by Agreement, Oxford: Clarendon Press, 1986; K. Binmore, Bargaining and Morality, in Gauthier - Stgden (eds.). Rationality, Justice and the Social Contract, New York/London: Harvester Wheatsheaf, 1993, 131-156

46 Tugendhat, op. cit., p. 11.

4 Ibidem, 13-14. 
O ćclat com a Doutring do Dircito não pode ser maior. Na verdade, observa Kant, a lei da justiça, contida no imperativo "dá a cada um o que é seu (sulum cuique tribule)", contém uma redundância normativa, "pois nào se pode dar a ninguém algo que já tem". Em sua obstinação de assegurar universalmente direitos igualitários, Tugendhat acaba vinculando todos os homens indistintamente a obrigaçöes recíprocas. Se a fórmula ulpiana é para ter um sentido, escreve Kant, ela deveria rezar como segue: "Inģressis numa situação, na qual a cada um pode ser sarantido (grifo J. N. Heck) o seu perante qualquer outro (Le'x institine')" th.

Um circulo analiticamente esclarecido não deixa de ser um círculo. É normal ver a pedra da sabedoria na coerção social, quando um conceito forte de razão - com pretensões à universalidade - é esclarecido com os recursos fracos de práticas lingüísticas familiares. Desde que usada para afigurar fatos, a linguagem do nonsentse moral das proposiçóes sintéticas a priori adquire erroneamente a dignidade de um objeto. Uma concepção uniforme de normatividade não permite conceber direitos não originados de obrigações coletivas mútuas. O normativismo de Tugendhat oscila constantemente entre a formulação descritiva de um meta-enunciado prescritivo e a verificação de sentimentos com propriedades normativas.

Contra tal redundância normativa, Kant estabelece a foncstas jurition como dever-mor do direito: "Não te faças para os outros um simples meio, mas sê para eles ao mesmo tempo fim". A essa obriģaz̧ă primordial não corresponde um direito alheio. O primeiro dever jurídico (Rechtspflicht) não é elucidado por Kant em correlação a algum direito, mas entendido "como vinculação oriunda do diréto da humanidade em nossa própria pessoa (als Verbindlichkeit aus dem Rechte der Menschlle't in unserer etgenlen Porson ... $)^{\text {tw }}$.

\section{A proposta da complementaridade entre moral e direito}

Habermas estabelece relaçōes com a Doutrina do Direito no âmbito da reconstrução do direito moderno. Na fase imediatamente anterior a essa reconstrução, o filósofo hipertrofia por mais de uma década a moral kantiana como critério distintivo da teoria consensual do discurso e do agir comunicativo. A partir de Facticidade é anlidade (1992), a democratização da sociedade não está mais subordinada à moral, mas é confia-

ti KiNit, op. cit. (237, 6-9), 46 .

${ }^{19}$ Ibidem $(236,25-34)$. 
da por Habermas ao direito. Marcando sua posição em relação ao uso ambíguo da expressão "direitos" em sentido moral e juridico, Habermas é enfático: "Ao invés disso, prefiro distinguir de saída entre direito e moral", e esclarece que tampouco se satisfaz com a distinção rawisiana entre moral e justiça política. "Por direito", define Habermas, "entendo o moderno direito normatizado, que se apresenta com a pretensão à fundamentaçào sistemática, à interpretação vinculadora e ao caráter impositivo (Durctsetzung)" "i". Para Habermas, a ética do discurso e o agir comunicativo adquirem maioridade concepcional nos modernos sistemas juridicos. Esses tornam-se autóctones, vale dizer, a figura moral do homme fica aos cuidados do citoye't.

Ao reconstruir o direito moderno com os recursos da ética discursiva e do agir comunicativo, Habermas é menos técnico do que à primeira vista possa parecer. Sua reconstruçào ignora as teorias psicológicas e sociologicas no direito moderno, e menospreza as diversas formas de jurisprudência pragmática na tradição jurídica alemã. O teórico do moderno sistema dos direitos tece a sua reconstruçào amparado por um pressuposto democrático, de acordo com o qual o complexo dos direitos subjetivos da Modernidade, ratificados moralmente pela Dontring to dircito, é caracterizado por uma falta de solidariedade (Solitaritiztslick $k$ '), que, segundo Habermas, já no direito racional kantiano é compensada pelo princípio da democracia nas pegadas da soberania popular de Rousseau (1712-1778).

Rompido uma vez o cordão umbilical entre direito e moral, a reconstruçào habermasiana estiliza dois tipos de direitos: ao primeiro equivalem os direitos da legislaçăo jurídica kantiana, agrupados por Habermas sob o termo legalidade; o segundo tipo é constiturdo pelos direitos do cidadão (Strnatshïrgertechto), totalizados em Habermas pelo designativo legitimidade. Enquanto o primeiro grupo aufere sua legitimação da liberdade do arbitrio (Willkitificille't), legalizada pela live escolha de motivos para o agir, a legitimidade dos direjtos integrantes do segundo grupo requer, para Habermas, autonomia política, e não apenas a legalizaçào da liberdade privada de fazer ou deixar de fazer.1. Com isso, a reconstrução habermasiana do direito moderno recebe a tarefa específica de "mostrar que o princípio da democracia não pode ser subordinado ao princípio moral, como ocorre na construção kantiana da Dentrina de Dirrite"s?

\footnotetext{
"HabEhus, Faktizitat und Geltung. Beiträge zur Diskursthoorie des Rechts und Les demokratischen Rechtsstaats, Frankfurt a/Main: Suhrkamp, 31993, 106. Trad do alemão por Flávio B. Siebeneichler, Rio de Janeiro: Tempo Brasileiro, 1997, p. 110.

st Ibidem, 51; versäo portuguesa, p. 54.

Ibidem, 111: versão portuguesa, p. 116.
} 
Esclarecida a tarefa, o teórico do direito configura a hipótese operacional. Para Habermas, regras morais e regras juridicas procedem simultaneamente, por um processo conceitual de diferenciação histórica, do mesmo universo ético tradicional e afirmam-se complementares, năo obstante constituam dois tipos diferentes de normatividade. A corroboraçào programática da hipótese exige, segundo Habermas, "que o conceito de autonomia seja concebido tão abstratamente que possa assumir cada vez mais, tanto em relação a uma quanto a outra espécie de normas de açào, uma figuração específica, a saber, por um lado figurar como princípio da moral e, por outro, como princípio da democracia ${ }^{\prime \prime}$.

$O$ conceito de autonomia, assim introduzido, adquire polivalência e torna-se oniabrangente, já que é destinado a manter moral e direito numa relação de complementaridade, ou seja, ambos são postulados em princípio como auto-sustentáveis, ficando sua recíproca interdependência submetida à regência autônoma do respectivo princípio normativo. Habermas constata, entào, lapidarmente: "Na sua 'Introdução à Metafísica dos Costumes', Kant procede diferentemente", ao partir dos conceitos superiores da teoria moral e restringi-los sob três pontos de vista no principio do direito. "Restringida dessa maneira", continua Habermas, "a legislação moral reflete'se' na juridica, a moralidade na legalidade, os deveres da virtude nos deveres do direito "ił. Por mais compreensivel que tal construção platônica se afigure para flabermas - intuindo a ordem juridica como cópia e concretização fenomenal da ordem inteligível de um "reino de fins" -, o teórico do direito considera que a subordinação do direito à moral é inconciliável com a idéxa de autonomia que se realiza no métinm do próprio direito. "A idéia dé que existe uma hierarquia de leis" é falsificada por Habermas com a observação de que cla "faz parte do mundo pré-moderno do direito ${ }^{\prime \prime}=$.

A hipótese sócio-histórica de Habermas, tentando reconstruir o surgimento do normativismo jurídico paralelo ao deontologismo moral, não é refutável com base na ciência kantiana do direito, uma vez que o conceito-chave da autonomia prática do homem como ser racional é consolidado na doutrina moral de Kant em desconsideraçào a qualquer ponderação de ordem jurídica. A tese da independência da Doutrintr do Dircito frente ao conceito positivo de liberdade, própria da segunda Criticn, justifica tanto a objeção de um suposto déficit liberal quanto uma crítica à suposta carência do agir solidário na filosofia prática do Kant. A proposta tardia de Habermas, no sentido de que a moral dos direitos subjetivos e a cidadania dos direitos democráticos venham a

Ibidem. 135-136; versão portuguesa, p. 139.

Ibidem, 136; versão portuguesa, p. 140.

Ibidem, 137; versão portuguesa, p. 141. 
ser concebidos como complementares à luz do conceito universalizável da autonomia política, tem a seu favor a concepção de um direito originário na ciência kantiana do direito. O conceito de humanidade, que suporta a definição kantiana do direito inato da liberdade, como independencia de cada homem diante do arbítrio constrangedor de qualquer outro, não é articulado em nenhuma passagem da Dontrina do Dircito como fonte geradora de obrigatoriedade moral. A hipótese genealógica de Habermas acerca do moderno paralelismo entre moral e direito confere com a posição da ciência kantiana do direito, quando Kant concebe a liberdade inata do homem pri possu com a lei geral do direito originada do imperativo categórico ${ }^{n}$.

Sob este aspecto, a reconstrução do moderno sistema dos direitos segundo os princípios da ética discursiva produz um $n$ zon $m$ ma filosofia política habermasiana. As reconstruções morais das décadas anteriores, feitas sob um backgound piagetiano e ou kohlbergiano, integram a moderna psicologia do desenvolvimento e não têm a mínima conotação com um sistema articulado de direitos na Modernidade. A tardia irrupção do direito no pensamento de Habermas torna, de chofre, anacrônicas posiçōes normativas aparentemente consolidadas em sua obra.

O máximo, porém, que é possível subtrair da tese da independência do conceito negativo de liberdade é a origem não moral dos direitos humanos inscritos por Habermas na prática da autodeterminação democrática dos cidadãos. Mais explicitamente do que em Facticitadé 'o culidate, Habermas computa efetivamente tal ganho programático para o direito racional kantiano em $A$ inclusino do ontro (1996). No âmbito de uma decisiva polêmica contra as teses de C. Schmitt (1888-1985) relativas à demarcação das fronteiras entre moral e direito, Habermas localiza a fonte dos direitos humanos no chäo nativo da normatividade jurídica, e ratifica: "Em Kant os direitos humanos encontram conseqüentemente o seu lugar na Doutrina do Direits, e tão-somente aqui"iz.

Em contrapartida, a proposta de sanar o suposto estreitamento teóricomoral na ciência kantiana do direito, mediante um conceito mais genérico e neutro de autonomia, não prospera sob o regime crítico kantiano. Não é plausivel que normas, que poderiam ter recebido anuência raci-

\footnotetext{
"1 Lowis, Kants Rechtslehre, Hamburg: Meiner, 1988, 104: "Das angeborene Recht der Menschheit wird nicht etwa aus dem allgemeinen Rechtsgesetz abgeleitet, sondern findet sich systematisch auf derselben Ebene".

"Harewnas, Die Einbeziehung des Anderen. Studien zur politischen Theorie, Frankfurt a/Main: Suhrkamp, 21997, 225: "Bei Kant finden Menschenrechte konsequenterweise ihren Platz in der Rechtslehre, und nur hier". Para a crítica dessa posição com base na contraproposta de Tugendhat, limitada ao processo de implementaçāo dos direitos fundamentais em Facticidade e validade, of. Maria C. MARqles-Dias, Ética do discurso: uma tentativa de fundamentação dos direitos básicos, Sintese Nova Fase, v, 22, n. 68 (1995): 87-100.
} 
onal em uma democracia participativo-deliberativa, mas deixaram de ser aprovadas factualmente, não possam ser consideradas moralmente legítimas, não obstante careçam da efetiva legitimação política. Tampouco é plausível que normas referendadas por via popular direta, mas sem serem ratificadas racionalmente, não sejam nulas no Estado de direito, muito embora possam parecer legítimas para quem participou de sua aprovação democrática.

Mais do que sinalizar um paradoxo político-racional, a idéia habermasiana de converter o conceito estritamente moral de autonomia em proveito da radicalização democrática evita o confronto sistemático com a autorização de coagir, segundo Kant, intrínseca a toda a legislação jurídica. Enquanto Kant confronta moralmente o indivíduo com todos os seres racionais via imperativo categórico, Habermas lida com generalizações lógico-abstratas tão-somente na medida em que abandona constelações discursivas específicas e rompe com as configurações circunstanciadas do agir comunicativo, próprias ao procedimento democrático. Kant não demonstra a faculdade de coagir nos parágrafos B-E da introdução à Doutrina do Direito pela reconstrução de relações dialógicas duais ou multifacetadas no plano de uma universalizabilidade políticonormativa, mas o faz concebendo a lei geral da coercibilidade jurídica oriunda da razão prática, logicamente anterior ao contrato social e, portanto, alheia à eventual atuação democrática de cidadãos nos respectivos Estados de direito porventura existentes sobre o planeta.

O calcanhar-de-Aquiles da reconstrução habermasiana da gênese lógica dos direitos, com um conceito de autonomia indiferente à moral e ao direito $^{58}$. está na incapacidade de fundamentar, com tal neutralidade conceitual, uma restrição a priori do uso legítimo da força entre seres racionais. Só a autodeterminação da vontade, assim como Kant formula na segunda Crítica, fixa os limites morais com vistas à faculdade recíproca e intersubjetiva de um ser humano constranger legalmente os demais e de ser por eles fisicamente constrangido. É um fato empírico que os homens submetam uns aos outros à força, assim como o fazem com animais, plantas e coisas a bel-prazer. O que distingue seres racionais do resto do mundo é que a nenhum deles cabe violar a esfera de autonomia da possível autodeterminação moral de seus semelhantes. Visto sob o prisma moral, o liberalismo jurídico de Kant só pode ser descrito negativamente, a saber: "A lei do direito formula os limites morais do possivel uso da força contra seres livres, isto é, 'na idéia' (...) o agir de outros está limitado àquelas ações que não atingem a esfera de minha possível autodeterminação moral ${ }^{1 / 59}$. A descrição positiva de liberdade

5* InEM, Faktizität und Geltung, 154; versão portuguesa, p. 158.

:3 Linwig, op. cit., p. 101. 
equivale em Kant ao fato da razão, de acordo com o qual a liberdade cognoscivel por lei moral é a liberdade efetiva de seres humanos.

O pêndulo da teoria da complementaridade tende em Habermas ostensivamente para o lado do direito, com a conseqüência de que a faculdade de coagir encontra no Estado de direito seu agente exclusivo. Tal estado de coisas honra o constitucionalismo moderno, mas desacredita a maneira como Habermas veicula, filosoficamente, o agir comunicativo na esfera do direito positivo. Os indícios desse descrédito são as afirmaçōes estereotipadas ao longo de Facticidade e validtade, segundo as quais o que fere a moral agride também o direito, plagiando declarações nos manuais de direito ou, numa versão mais democratizante, reforça o já clássico repertório do clamor por mais ética na política.

Na verdade, o teórico do direito arrasta atrás de si resoluções de problemas filosóficos adiadas. Em Consciència momal e aģir comnnicatizo (1983), Habermas lança mão de uma objeção-chave para justificar por que sua compreensão ético-discursiva não constrói in toto sobre a contradição performativa, articulada por K.-O Apel (1922-) contra a posição teórica do cético. Depois de introduzir a questão da validade de uma norma de ação com o exemplo da liberdade de expressão, sancionada pelo Estado como direito fundamental, Habermas escreve que "não é, de modo algum, óbvio que regras inevitáveis no interior (inncrhall) de discursos possam também reclamar validade para a regulação do agir forn (anusserthalb) de argumentaçōes". Para Habermas, mesmo que participantes de uma rodada argumentativa sejam forçados a se submeter a pressupostos normativos, eles não mais estão vinculados a tais constrições pragmático-transcendentais a partir do momento em que abandonam o círculo da argumentação, pois "aquela coação (Nötiguning') não se transfere de imediato do discurso para o agir". Habermas conclui, observando: "De qualquer maneira, a força rę̧ulatom do açâo do conteúdo normativo, trazido à luz nos pressupostos pragmáticos da arģzunlentação, necessitaria de uma fundamentação particular"til. Em suma, se Habermas viesse a assumir a força coativa da contradição performativa como igualmente constringente no âmbito da ação humana, o conceito de agir comunicativo não passaria de uma redundância terminológica de sua concepção ético-discursiva ${ }^{\text {thl }}$.

A relevância da objeção torna-se clara quando Habermas explica o apego obstinado à pragmática transcendental como sendo um retorno

(6: Habeinas, Moralbewusstsein und kommunikatives Handeln, Frankfurt a/Main: Suhrkamp, 1983, 96. Trad. do alemão por Guido A. de Almeida, Rio de Janeiro: Tempo Brasileiro, 1989, p. 109.

${ }^{6 !}$ Cf. D. Dutra, Demonstrar por refutação, in L. C. Bombassako - J. Paviani (orgs.). Filosofia, lógica e existência. Homenagem a Antônio Carlos Kroeff Santos. Caxias do Sul: EDUCS, 1997, 48-66. 
inconseqüente a figuras do pensamento que o próprio Apel "invalidara ao levar a cabo uma enérgica mudança de paradigma da filosofia da consciência para a filosofia da linguagem ${ }^{\prime \prime 2}$. Posicionado como um kantiano, Habermas reconstrói em poucas linhas, com a história da filosofia, a gênese do mal-entendido pragmático de Apel, reportandose à investida ético-idealista de Fichte (1762-1814) sobre o Faktum da razão em Kant. Não obstante Apel fale do dogmatismo metafísico residual de Fichte, expõe Habermas, "ele baseia, se entendo bem, a pretensão de fundamentação última da pragmática transcendental exatamente nessa identificação reflexiva de uma operação previamente efetuada de maneira intuitiva, isto é, tão-somente sob as condições da filosofia da consciência"th.3. Com isso Habermas realça, afastando-se de Apel, a posição definitiva da segunda Crítiç de Kant para a esfera do agir humano.

Na posterior reconstrução do direito moderno, com base no conceito do discurso (Diskursbegriff), o teórico do direito fica devendo o que objetara anteriormente a Apel. A obra jurídica de Habermas não apresenta uma concepção de agir comunicativo que sustente moralmente o convívio humano. Ao atribuir à versão kantiana do contrato social um caráter performativo, Habermas limita-se a ratificar o significado da contradição performativa ${ }^{\text {h.t. }}$. Como, para Kant, iustum et iniulustum! permanecem imunes ao contratualismo, Habermas assume, na contramão de Apel, o jusnaturalismo kantiano na esfera da ética discursiva.

Avaliadas retrospectivamente, as tentativas ${ }^{6 \bar{n}}$ de dar sustentação moral ao agir comunicativo com os recursos da filosofia prática de Kant chegam à exaustão em Facticidade e znlidade. $\mathrm{O}$ indicativo de Habermas de que constitutos jurídico-institucionais devam ser aceitos por seu caráter pós-metafísico afigura-se estratégico e, como tal, é pouco convincente, mesmo para simpatizantes da democracia radical ${ }^{\text {s. }}$. Uma explicação à primeira vista plausível, para o fato de Habermas acolher a posição kantiana no tocante à liberdade como único direito inato do ser

${ }^{62}$ Habermas, op. cit., 106; versão portuguesa, p. 119.

i3. IbIdem,

"HABERAs, Faktizität und Geltung, 122: "Kant zufolge einigen sich die Parteien nicht auf die Einsetzung eines Souveräns (...). Der Gesellschaftsvertrag (...) legt performativ die Bedingungen fest, unter denen Rechte legitime Geltung erlangen"; versão portuguesa, p. 126.

65. Cf. em especial "Moralbewusstsein und kommunikatives Handeln", in op. cit., pp. 127-206, e "Treffen Hegels Einwände gegen Kant auch auf die Diskursethik zu?", in Erläuterungen zur Diskursethik, Frankfurt a/Main: Suhrkamp, 1991, pp. $9-30$.

tif LAKMokE, Die Wurzeln radikaler Demokratie, Deutsche Zeitschrift für Philosophie, Heft 41, Bd. 2 (1993): 324: "Diese Taktik scheint mir ein Fehler zu sein". 
humano, é a justificação moral que Kant oferece para a faculdade de coagir no âmbito da legislação externa. Contra tal plausibilidade, pode, porém, ser aventado que Habermas, já no início da década dos anos oitenta, busca o contato da dialética do reconhecimento. "O cognitivista ponderado", escreve Habermas, "não hesitará em dar um passo em direção às considerações bem dosadas de seu oponente" ${ }^{\prime \prime}$. Vistas à luz das objeções que Hegel faz ao formalismo kantiano, Habermas suprassume a coerção legal na determinidade do conceito. Da autocoação moral (Selbstzwang) e da coerção jurídica (Fremdziunng) restam ícones pós-metafísicos. Um dos interlocutores mais razoáveis de Habermas, prezando abertamente sua filosofia política como teoria da ação comunicativa, enquadra conseqüentemente a trajetória habermasiana na segunda alternativa. "Habermas's own doctrine", assevera Rawls (1921-), "is one of logic in the broad Hegelian sense $(\ldots)^{\prime \prime \text { int }}$.

A despeito dos indícios de que o teórico do direito continue reescrevendo a Dialética do esclarecimento no estilo hegeliano ${ }^{\text {ty, }}$, suas oscilações entre moral e direito acontecem sob o regime de Kant ou, como Habermas prefere dizer, ocorrem "no espírito kantiano"7".

Com a proposta de que moral e direito são complementares, Habermas reescreve na verdade sua concepção de modernidade filosófica. O projeto kantiano não é mais avalizado pela dialética posterior, mas ratificado como matriz determinante da razão moderna, paulatinamente avessa à indistinção entre moral e direito. A posição contrária Habermas ainda a assume em $O$ discurso filosófico da modernidade (1986), ao atribuir a Hegel a radicalização de uma razão cindida em Kant, como pressuposto racional da impulsividade transformadora do espírito moderno $^{71}$. No prefácio de sua obra jurídica, Habermas se autodespede do espírito objetivo com um understatement, seguido por uma constatação programática elementar. Depois de assinalar que o nome

6ĩ Habermas, Moralbewusstsein und kommunikatives Handeln, 87; versão portuguesa, pp. 98-99

6ix J. Rawls, Reply to Habermas, in Political Liberalism, New York: Columbia University Press, 1996, 378. Cf. também Habfrmas, Politischer Liberalismus. Eine Auseinandersetzung mit John Rawls, in Die Einbeziehung des Anderen. Studien zur politischen Theorie, Frankfurt a/Main: Suhrkamp, 1997, 65-127.

69 Cf. N. F. Oufveira, Mundo da vida: a apropriação habermasiana de Husserl e Wittgenstein, Veritas, v. 44, n. 1 (1999): 133-145.

7) Habermas, Erläuterungen zur Diskursethik, Frankfurt a/Main: Suhrkamp, 1991, 100: "(Die Diskursethik nimmt) Hegels Theorie der Anerkennung für eine intersubjektivistische Lesart des kategorischen Imperativs in Anspruch, ohne dafür den Preis einer historischen Auflösung von Moralität in Sittlichkeit zu entrichten. Sie behart wie Hegel auf dem inneren Zusammenhang von Gerechtigkeit und Solidarität, aber im Kantischen Geiste".

it Cf. R. R. Terra, Notas sobre sistema e modernidade. Kant e Habermas, Filosofia Politica Nova Fase, v. 4 (1999): 58-64. 
de Hegel quase não aparece no livro, e que o trabalho se apóia na doutrina kantiana do direito, o autor justifica sua atitude com "a apreensão (Scheu) perante um modelo que estabeleceu para nós padrões inatingíveis", apostrofando lapidarmente: "Não é, em verdade, nenhuma casualidade que a filosofia do direito, lá onde ela ainda busca o contato com a realidade social, emigrou para as faculdades de direito" ${ }^{\prime \prime 2}$.

A reapropriação da postura crítica de Kant, por parte do teórico do direito, não sinaliza um turn a mais na trajetória intelectual de Habermas, mas tem a feição de uma declaração de princípios. Na laudatio em homenagem a Apel, Habermas registra sem rodeios que a espantosa segurança de discernimento do homenageado deve-se à orientação que lhe advém de Kant, "o mais lúcido e insuspeito espírito da Aufklärung alemã"73. Tomada a sério, a caracterização enfática do pensamento kantiano não só encurta a distância que separa Habermas da Escola de Frankfurt, mas também lhe impõe a tarefa de levar a cabo a Dialética do esclarecimento (1944) com a Doutrina do Direito de Kant, um empreendimento apenas entrevisto por Adorno (1903-1969) e inconcebível para Horkheimer (1895-1973).

A tese maior de Faticidadde $e$ validade, segundo a qual a soberania popular tem primazia sobre os direitos subjetivos, faz mais justiça a Rousseau do que a Kant. O republicanismo rousseauniano distingue-se do kantiano pela socialização da legislação política. Tãosomente a rigorosa uniformização da consciência dos cidadãos pela aliénation totale possibilita, em Rousseau, uma legislação única e congraçadora. Kant, em contrapartida, concebe o poder legiferante como autonomia atribuída não a indivíduos, mas sim a princípios e instâncias legisladoras, e apenas na medida em que são aceitáveis para todos. A idéia kantiana de autodeterminação política toma por referência uma racionalidade jurídica procedural, não tendo por objeto processos societários reais. Trata-se, para Kant, de agir em conformidade com princípios que possam ser aceitos por todos, e não de propor que se aja por princípios cuja aceitabilidade seja certificada por todos ou esteja submetida a um procedimento democrático.

A crux da doutrina kantiana do direito é seu intrínseco liberalismo. Há tão pouco a democratizar na posição jurídica de Kant quanto inexiste

\footnotetext{
72 Habermas, Faktizität und Geltung, 9; "Es ist ja kein Zufall, daß die Rechtsphilosophie dort, wo sie den Kontakt mit der gesellschaftlichen Realität noch sucht, in die Juristischen Fakultäten abgewandert ist"; versão portuguesa, p. 9

73. IDEM, Vom sinnlichen Eindruch zum symbolischen Ausdruck. Philosophische Essays, Frankfurt a/Main: Suhrkamp, 1997, 93.
} 
algo a dialetizar em sua posição moral. Ambas estão inexoravelmente comprometidas com a noção exigente de liberdade e da independência radical de cada homem perante seu semelhante.

Auto-situado entre liberais e comunitaristas, Habermas administra o legado kantiano da razão prática com um conceito de democracia radical, assegurado pelo caráter procedural da razão comunicativa. $O$ teórico do direito marca o contraste em relação a Kant destranscendentalizando o reino do inteligivel por meio da soberania popular, materializada na associação política dos cidadãos. O clássico elenco dos direitos subjetivos (liberdade de consciência, de expressão, de associação, bem como a propriedade privada) é ora articulado como pressuposto, ora como resultante da soberania popular, jamais concebido como limitador da autonomia democrática. Para Habermas, somente pela última o Estado de direito adquire uma base normativa. Com isso, tanto a concepção kantiana de moral quanto a de direito ficam subordinadas à soberania popular e sua racionalidade comunicativa. Em suma, ambas constituem a matriz normativa da política deliberativa no Estado democrático.

Habermas reivindica, na esteira de Kant, uma posição crítica para sua reconstrução do direito moderno. As razões aduzidas para sustentar essa pretensão não merecem crédito. Habermas não informa por que determinadas estruturas de pensamento e de ação valem como racionais e outras não, isto é, o teórico do direito não esclarece a autoridade que assiste à razão comunicativa. A tese da neutralidade procedural pós-metafísica não faz jus à crítica cultural que ainda ampara, em Rousseau, a solução política. Ancorado sobre a tipologia weberiana da modernidade cultural, Habermas se exercita numa espécie de dialética regressiva, projetando para a atualidade o evento da razão finita e falível dos tempos inaugurais da Modernidade. Sob este aspecto, soa resignativo que perguntas cruciais da teoria moral devam, segundo Habermas, ser repassadas para a filosofia do direito, "pois de maneira inequívoca a unidade da razão prática só pode alcançar validade na concreção daquelas formas comunicacionais e práticas dos cidadãos, nas quais as condiçóes de formação racional coletiva da vontade adquiriram solide $\%$ institucional ${ }^{74}$.

O repasse normativo só permanece (riftico, na medida em que zela pela unidade da razão, uma vez que quaisquer formas constatáveis de socialização, de autocompreensão política e auto-organização democrática podem estar erradas, fracassar ou acabar em tragédia. A mais bem consolidada associação política não pode dispensar a lex iuritica maior que proibe fazer injustiça a quem quer que seja (n'mint'm lnc'tc), ainda

i- IıEM, Erläuterungen zur Diskursethik, 118. 
que, segundo Kant, "devesses abandonar por isso toda relação com outros e teres de evitar qualquer companhia"75.

O rigorismo kantiano tem caráter jurídico. Ele vincula os seres humanos à revelia de toda associação política.

\section{Observações conclusivas}

Por mais que Tugendhat e Habermas divirjam em suas recepçōes da doutrina kantiana do direito, ambos têm o mérito de manter intactas as relaçóes entre direito e moral, evitando, por um lado, assumir uma posição jusnaturalista que isola o direito da moral e, por outro, descartando a posição dialética que suprassume a moralidade no moderno ethes do espírito objetivo.

Tugendhat procura resgatar sobre uma base sólida a pretensão de validade de nossas intuiçóes morais, tendo em vista um sistema de direitos norteados pelo respeito universal e igualitário da pessoa humana. Para Tugendhat, toda vinculação prescritiva obedece a um senso uniforme, ainda que não homogeneizado, de normatividade. Embora combata rudemente a doutrina dos dois reinos, Tugendhat reescreve constantemente a distinção entre o modo como o mundo é e como deve ser. Como rejeita o papel cognitivo atribuido por Kant à lei moral, Tugendhat também não elabora nenhuma noção de norma jurídica. Intuitivo ou reflexivo, seu normativismo é menos deôntico do que teleológico, e acena para uma concepção de perfeccionismo, cuja unidade orgânica já Aristóteles suspeita que está fundada no brón humano.

Habermas estabelece as relaçóes entre direito e moral mediante um procedimento que difere do modo concebido por Kant de conectar legislação interna e legislação externa, mas continua remetendo a racionalidade jurídica à normatividade da moral, e transfere para a esfera do direito o loctss que a razão prática ocupa na arquitetônica kantiana. Embora não abone a priorização dos direitos subjetivos na Doutrina do direito, Habermas acaba privilegiando a validade das normas jurídicas em detrimento da imperatividade do agir moral. Ao passo que a concepção kantiana de razão é eminentemente prática, Habermas revalida a segunda Crifica como instância fundadora de uma racionalidade intersubjetiva que abrange ética, política e práticas lingüisticas.

\footnotetext{
5 Ka`T, Metaphysische Anfangsgründe der Rechtslehre (236, 33-35), 46.
} 
Essa razão comunicativa só poderá ainda honrar o Faktum da razão, se não apenas legislar por meio de normas justas, mas também fizer justiça a cada homem. Decerto Kant fica devendo uma explicação para o fato de que a razão prática fundamenta leis da liberdade, mas não gera automaticamente direitos democráticos. Em contrapartida, Habermas não esclarece por que a razão comunicativa não aplica ipso facto, em cada caso, as normas estabelecidas pelo princípio democrático.

\section{Referências bibliográficas}

BECKENKAMP, Joãosinho. Tugendhat, leitor de Aristóteles. Dissertatio, n. 3 (1996).

BINMORE, Ken. Bargaining and morality. In: GAUTHIER — SUGDEN (eds.). Rationality, Justice and the Social Contract. New York/London: Harvester Wheatsheaf, 1993.

DEGGAU, Hans G. Die Aporien der Rechtslehre Kants. Stuttgart: Reclam, 1983.

DUTRA, Delamar. Demonstrar por refutação. In: BOMBASSARO, Luiz C. - PAVIANI, Jayme (orgs.). Filosofia, lógica e existência. Homenagem a Antônio Carlos Kroeff Santos. Caxias do Sul: EDUCS, 1997.

GAUTHIER, David. Morals by Agreement. Oxford: Clarendon Press, 1986.

GÜNTHER, Karl. Kann ein Volk von Teufeln Recht und Staat moralisch legitimieren? Rechtshistorisches Journal, Heft 10 (1991).

HABERMAS, Jürgen. Moralberousstsein und kommunikatious Handeln. Frankfurt a/Main: Suhrkamp, 1983. Trad. do alemão por Guido A. de Almeida. Rio de Janeiro: Tempo Brasileiro, 1989.

1991.

Erläuterungen zur Diskursethik. Frankfurt a/Main: Suhrkamp,

Faktizität und Geltung. Beiträge zur Diskurstheorie des Rechts und des demokratischen Rechtsstaats. Frankfurt a/Main: Suhrkamp, ${ }^{3} 1993$. Trad. do alemão por Flávio B. Siebeneichler. Rio de Janeiro: Tempo Brasileiro, 1997.

Normalität einer Berliner Republik. Kleine Politische Schriften VIII. Frankfurt a/Main: Suhrkamp, 1995.

Die Einbeziehung des Anderen. Studien zur politischen Theoric.

Frankfurt a/Main: Suhrkamp, ${ }^{2} 1997$. 
Vom sinnlichen Eindruck zum symbolischen Ausdruck. Philosophische Essays. Frankfurt a/Main: Suhrkamp, 1997.

HÖFFE, Otfried. O imperativo categórico do direito: uma interpretação da "Introdução à Doutrina do Direito". Studia Kantiana, v. 1, n. 1 (1998).

HURKA, Thomas, Perfectionism. Oxford: Oxford University Press, 1993.

KANT, Immanuel. Kritik der praktischen Vernunft. Hrsg. von Karl Vorländer. Hamburg: Meiner, ${ }^{9} 1969$. Trad. do alemão por Artur Morão. Lisboa: Edições 70, 1989.

A paz perpétua. In: Kleinere Schriften zur Geschichtsphilosophie, Ethik und Politik. Hrsg. von Karl Vorländer. Hamburg: Meiner, 1973. Trad. do alemão por Artur Morão. Lisboa: Edições 70, 1988.

Metaphysische Anfangsgriunde der Rechtslehre. Hrsg. von Bernd Ludwig. Hamburg: Meiner, 1986.

KERSTING. Wohlgeordnete Freiheit. Immanuel Kants Rechts und Staatsphilosophie. Berlin/New York: de Gruyter, 1984.

LARMORE, Charles. Die Wurzeln radikaler Demokratie. Deutsche Zeitschrift für Philosophie, Heft 41, Bd. 2 (1993).

LUDWIG, Bernd. Kants Rechtslehre. Hamburg: Meiner, 1988.

MARQUES-DIAS, Maria C. Ética do discurso: uma tentativa de fundamentação dos direitos básicos. Sintese Nova Fase', v. 22, n. 68 (1995).

OLIVEIRA, Nythamar Fernandes de. Mundo da vida: a apropriação habermasiana de Husserl e Wittgenstein. Veritas, v. 44, n. 1 (1999).

O'NEILL, Onora. Kommunikative Rationalität und praktische Vernunft. Deutsche Zeitschrift fiir Philosophie, Heft 41, Bd. 2 (1993).

RAWLS, John. Reply to Habermas. In: Political liberalism. New York: Columbia University Press, 1996.

TERRA, Ricardo R. Notas sobre sistema e modernidade. Kant e Habermas. Filosofia Politica Nova Fase, v. 4 (1999).

TUGENDHAT, Ernst. Gibt es eine moderne Moral? Zeitschrift fïr philosophische Forschung, Bd. 50 (1996).

Vorlesungen über Ethik. Frankfurt a/Main: Suhrkamp, ${ }^{3} 1995$.

Trad. do alemão por Ernildo Stein et al. Petrópolis: Vozes, 1997.

Dialog in Leticia. Frankfurt a/Main: Suhrkamp, 1997. 
Igualdade e universalidade na moral. BRITO - HECK. Ética c' politica. Goiânia: Editora UFG, 1997.

. Reflexões sobre o que é que significa justificar juízos morais. Goiânia, 1998 (mimeo).

O contratualismo na moral. Caxambu, 1998 (mimeo).

Ética e justificação. Verituss, v. 44, n. 1 (1999).

WELLMER, Albrecht. Ethik und Dinlogr. Frankfurt a/Main: Suhrkamp, 1986.

Findereço do Autor:

Av. T-4 \& T-65 - Setor Bueno

Ed. B. Landeiro, $1077 \mathrm{~A} / 903$

74230)-120 Goiânia - GO

‘-mail: heck@internetional.com.br 